O MUSEU E O EXERCÍcIO DE LIBERDADE: O trabalho de acessibilidade cultural do Museu de Arte Moderna de São Paulo.

THE MUSEUM AND THE EXERCISE OF FREEDOM: The work of cultural accessibility of Museu de Arte Moderna de São Paulo.

\title{
Daina Leyton
}

dainaleyton@gmail.com

Museu de Arte Moderna de São Paulo

\section{Resumo:}

O presente artigo apresenta o trabalho de educação de e acessibilidade cultural do Museu de Arte Moderna de São Paulo. No processo de idealização e construção de um Museu de Outra Percepção, nos deparamos com nossas limitações e aprisionamentos, que se iniciam no corpo de cada sujeito e se ampliam no corpo social. Os aprendizados que tivemos com públicos diversos que frequentam o museu, entre pessoas com deficiência, o público da saúde mental, e pessoas em situação de vulnerabilidade social, nos trouxeram reflexões sobre nossa liberdade e as várias maneiras que ela é cerceada. Essa foi a contribuição reflexiva trazida para os temas dos seminários: 30 Políticas Públicas para a Educação Penitenciária: Arte, Cultura e Educação Penitenciária e o IV Seminário de Artes Cênicas.

Palavras-chave: Acessibilidade Cultural, Educação, Liberdade.

\section{Abstract:}

This article presents the work of education and cultural accessibility of the Museum of Modern Art of São Paulo. In the process of idealization and construction of a Museum of Another Perception, we are faced with our limitations and imprisonments, that begin in the body of each beeing and extend to the social body. Our learning from the diverse audiences that visit the museum including people with disabilities, mental health audience, and people in socially vulnerable situations has given us reflections on our freedom and the various ways it is curtailed. This was the reflective contribution brought to the themes of the seminars: 3rd Public Policies for Penitentiary Education: Art, Culture and Penitentiary Education and the IV Seminar of Performing Arts.

Keywords: Cultural Accessibility, Education, Freedom.

Ao receber o convite para palestrar na abertura do 30 Seminário de Políticas Públicas para a Educação Penitenciária: Arte, Cultura e Educação Penitenciária, realizado junto com o IV Seminário de Artes Cênicas, me perguntei qual a contribuição mais significativa que eu, professora de acessibilidade cultural e atualmente coordenadora do Educativo e da Acessibilidade do Museu de Arte Moderna de São Paulo, poderia trazer. Sobre o 30 Seminário de Políticas Públicas para a Educação Penitenciária: Arte, Cultura e Educação Penitenciária, apesar de ter trabalhado durante 
minha graduação na Penitenciária I - Mário Moura Albuquerque ${ }^{1}$, essa é uma experiência longínqua, e certamente grande parte do público presente no seminário tinha mais proximidade e conhecimento sobre educação penitenciária do que eu. Já o tema do IV Seminário de Artes Cênicas é bastante próximo ao que realizamos cotidianamente no Museu de Arte Moderna de São Paulo, nos espetáculos, performances e cursos. Em conversa com Emerson de Paula ${ }^{2}$, considerando os temas de ambos os seminários pensamos que uma contribuição significativa seria trazer o que nós, do Museu de Arte Moderna de São Paulo, pudemos aprender em décadas de trabalho com arte e educação com diversos públicos, entre pessoas com deficiência, o público da saúde mental, pessoas em situação de vulnerabilidade social, e qualquer pessoa interessada em nossa grade de cursos, oficinas e outras programações culturais. Ou seja, compartilhar o que nós pudemos aprendemos sobre as nossas limitações e nossos aprisionamentos. Nos processos artísticos e educativos que desenvolvemos no museu, buscamos compreender o que normalmente é considerado limitação como potencialidade, como possibilidades. Nesse processo, pudemos constatar como cerceamos de diversas maneiras nossa liberdade e a dos outros, e assim refletir sobre como podemos transformar esse contexto. Para o tema do IV Seminário de Artes Cênicas, a contribuição vem dessa mesma percepção de nossa liberdade e aprisionamentos, porém com foco na forma que eles incidem e se encontram estruturados em nossos corpos, movimentos, expressão e comunicação. Unindo assim o tema de ambos os seminários, a proposta é refletir como esses cerceamentos e limitações se iniciam no corpo de cada sujeito, e se ampliam e reverberam no corpo social.

Iniciamos com uma provocação trazida pelo fotógrafo e filósofo cego Evgen Bavcar (2015), inspiração e referência para as ações de acessibilidade que desenvolvemos no MAM. Frequentador assíduo de exposições de arte e espaços culturais, Bavcar imagina e idealiza um museu que ele nomeia como O Museu de Outra Percepção, que seria:

“(...) um museu que traga abordagens diferentes das habituais, se ocupando de outras percepções, além daquela que é considerada 'normal' ". Um museu que transcenda a lógica "oculocêntrica" vigente nos museus, nos quais as obras são quase sempre expostas para a visão frontal, enquanto várias outras formas de percepção são possíveis, mas pouco exploradas. "(LEYTON, 2017, p. 236)

\footnotetext{
${ }^{1}$ Em Franco da Rocha- São Paulo

2 Professor assistente do curso de teatro da UNIFAP- área de prática pedagógica em Teatro, que participou da idealização e organização dos seminários.
} 
Segundo Bavcar, a lógica "oculocêntrica" domina os espaços culturais, uma vez que as obras de arte são quase sempre expostas para a visão frontal, contexto a que ele se refere como "Tirania Oculocêntrica Frontal" (BAVCAR, 2015). Afinal, mesmo obras tridimensionais como as esculturas, são na maioria das vezes expostas para serem exploradas pela visão: a maneira que elas são exibidas geralmente não instiga os outros sentidos. É como se estivessem destinadas " $a$ um olhar desejado pelo olho físico: o mundo 'oculocêntrico' é muito poderoso e domina atualmente todas as outras percepções e perspectivas, não somente as táteis" (BAVCAR, 2015, p. 43).

Bavcar atenta ainda para o fato de que até mesmo os dispositivos de acessibilidade, existentes em museus e centros culturais, são na maioria das vezes pensados na lógica das pessoas que não têm deficiência. E defende que esse contexto acaba por submeter as pessoas com deficiência ao que ele considera uma privação de liberdade.

\begin{abstract}
Atribuímos o termo "pessoa com deficiência" a quem está na situação de privação de liberdade. Uma das maiores privações de liberdade é a acessibilidade às obras de arte e à riqueza cultural do mundo. Estamos apenas começando a evocar esse problema, porque durante séculos fomos acostumados a ser silenciados e a ouvir os outros, fomos acostumados a que outros falassem em nosso nome, em vez de termos nosso próprio discurso, de nós mesmos falarmos sobre nossas necessidades, nossa liberdade e nossa escravidão - ou seja, nossa maneira de sermos privados da liberdade. O museu da outra percepção também pode englobar pessoas que enxergam de outro modo. Pessoas que enxergam de outro modo como as crianças, os cadeirantes, as pessoas que não possuem uma estatura média, supostamente normal, um museu onde elas poderiam ter a mesma perspectiva de todo mundo, mas isso ainda não existe. (BAVCAR, 2015, p. 43)
\end{abstract}

Levando em consideração os espaços culturais, compreendemos que essa privação de liberdade é imposta, e não precisaria ser assim. Afinal, se conseguirmos desenvolver espaços em que todos tenham equiparação de oportunidades, sem obstáculos físicos, comunicacionais ou atitudinais, podemos vislumbrar uma realidade muito diferente.

Como seria possível então desenvolver um Museu de outra percepção? o caminho que encontramos no MAM foi permanecermos atentos às diversas formas de estar no mundo, para assim percebermos como nós próprios contribuímos para o cerceamento de nossa liberdade e dos outros. O argumento de Bavcar nos leva também a ampliar essa reflexão para todos nós: não nos encontraríamos todos, em alguma instância, privados de liberdade? Interessante pontuar que 
costumo trazer há bastante tempo essa questão, em minhas palestras e aulas. No início, cerca de uns dez anos atrás, era comum as pessoas refletirem, e até mesmo ficarem em dúvida se realmente se encontravam nessa condição de privação de liberdade. Atualmente, quando pergunto a resposta costuma ser imediata e logo vejo as pessoas fazerem sinal positivo com suas cabeças. Essa pergunta se desdobra em outras: e qual seria a real acessibilidade que usufruímos? Ao direito de ir e vir? Ao nosso corpo? Aos nossos desejos? A falarmos com voz própria?

\begin{abstract}
Ao ampliarmos a questão para além das deficiências físicas, sensoriais e cognitivas, podemos constatar que são inúmeras as condições que cerceiam, de diferentes maneiras, nossa liberdade. A educação deficitária, a ausência da possibilidade de questionamento, o sentimento de não pertencimento, ou mesmo preconceitos e entendimentos "préfabricados" são alguns aspectos que acometem diferentes pessoas nas suas diversas histórias de vida, e que irão reverberar em sua visita ao museu e no que ali pode acontecer no contato com a arte. Se esses atravessamentos podem interferir na qualidade do olhar e da escuta e prejudicar a construção e sentido, como fomentar a fruição, o debate e a reflexão crítica? Considerando esses inúmeros distanciamentos a que nos encontramos submetidos em nossa realidade, o que um museu deve fazer para que a liberdade não seja cerceada? É possível dar-se tempo e espaço para que algo seja criado? (LEYTON; SANCHES, 2018, p. 115)
\end{abstract}

Após anos de trabalho nessa permanente busca de construir um museu para todos, o que afirmamos hoje, é que a acessibilidade para nós, não é apenas promover o acesso ao que já existe e ao que já está instituído. Se a realidade tal qual ela se encontra atualmente exclui tantas pessoas, nos cabe então buscar promover a acessibilidade no sentido de pensar, sonhar e idealizar a sociedade que desejamos, e como seria possível contribuir para que ela um dia se torne realidade.

Para a manutenção de uma ordem vigente, sabemos que as diferenças não costumam ser bem vindas. Esse argumento pode ser estudado nas análises sobre a criação de dispositivos de exclusão e controle, como as penitenciárias, os manicômios e os quartéis, encontradas em diversas obras do filósofo Michel Foucault, como a História da Loucura (1972), A sociedade punitiva, (1973), Vigiar e Punir - nascimento da prisão (1975), e Microfísica do Poder (1978). Nelas, Foucault esmiúça a função desses dispositivos que são locais onde os corpos podem ser vigiados e controlados, e acaba por estender essa reflexão também para as escolas. E vale pensarmos também aqui, como se posicionam os museus nesse contexto. Me aprofundarei um pouco mais sobre essas duas instituições (escola e museu), por compreender que elas podem servir tanto à manutenção, quanto ao questionamento da ordem vigente. 
Sobre a escola, ela pode ainda significar para grande parte do imaginário coletivo, uma instituição que promove de certa maneira um treinamento e adequação para a vida em sociedade. Essa seria a compreensão de uma certa escola-padrão que é criada em determinado contexto social e responde a suas demandas específicas:

\begin{abstract}
Nasce na virada do século XVIII para o XIX após a revolução industrial inglesa - com a expansão das redes de comércio e trabalho - e a revolução burguesa francesa - com a profunda modificação da função social dos sujeitos. Nesse contexto, a criação da chamada sociedade de massas e da hegemonização do poder do Estado centralizador cria a urgência de uma educação estruturada nas necessidades que esse Estado postula para seu desenvolvimento. Portanto, para treinar a mão-de-obra necessária nesse novo contexto econômico-social, criam-se instrumentos de serialização do saber e codificação corporal a fim de atingir a produtividade de interesse dos Estados, e um desses instrumentos é a escola moderna - pública, gratuita e para todos. (SANCHES, 2018, p. 54).
\end{abstract}

Porém, a escola como um espaço altamente instrumentalizador é um modelo que Jan Masschelein e Maarten Simons (2013), no livro Em defesa da escola: uma questão pública consideram escolas desescolarizadas ${ }^{3}$ : escolas que não buscam promover processos de construção de sentido, ou de tomada de consciência. Escolas essas, que vão na contramão da própria etimologia da palavra, que advém do latim schola ${ }^{4}$, derivada do termo grego skholé ${ }^{5}$, cujos significados indicam o conceito de "tempo livre", "lazer" e "ócio". (MASSCHELEIN E SIMONS, 2013)

\begin{abstract}
A escola é o tempo do ócio, o tempo que não serve e/ou não tem serventia a nada e a ninguém, apenas ser vivente nele. $O$ tempo da suspensão das normas e formas. $O$ tempo do acontecimento latente. A escola, como espaço de encontro, é o lugar onde as pessoas se despiam de suas codificações sociais e se encontravam em um espaço hierarquicamente justaposto, enquanto cidadãos livres (lembrando que, na antiga sociedade grega, apenas uma pequena parcela da população tinha o direito a esse título). A escola surge como um acontecimento e se retifica em um espaço dedicado à manutenção dessa dessujeição. (SANCHES ${ }^{6}, 2018$ apud LEYTON; ZARDO, 2018, P. 55)
\end{abstract}

Como instituição, a escola já passou por diversas compreensões e formatos. Pensando na questão dos nossos aprisionamentos e liberdades, se escola significa tempo livre, nos cabe refletir

\footnotetext{
3 “Na verdade, podemos ler a longa história da escola como uma história de esforços continuamente renovados para lhe roubar o seu caráter escolar, isto é, como tentativas de 'desescolarizar' a escola -que vão muito mais longe do que os autoproclamados 'desescolarizadores' da década de 1970 podiam perceber. " Jan Masschelein e Maarten Simons. Op. cit., pp. 27-28.

4 Etimologia extraída do livro Em defesa da escola: uma questão pública, de Jan Masschelein e Maarten Simons. 5 Ibid.

${ }^{6}$ Gregório Sanches. Educação em contextos não formais. In: Curso Museu aberto: empreendimentos criativos (Mediação cultural, Módulo 3), São Paulo, MAM, 2018.
} 
qual seria então a escola que desejamos e buscamos. Segundo Masschelein ${ }^{7}$ (2013 apud KOHAN, 2013, p. 2), a escola não existe para reproduzir a ordem social. Pelo contrário, ela possibilita um espaço e um tempo diferenciados que colocam de alguma maneira em questão os espaços e tempos sociais.

A escola compreendida como tempo livre é uma inspiração e referência que temos pautado nossa ação educativa no MAM. Afinal, um museu de arte moderna e contemporânea, deve ser compreendido como lugar de liberdade e experimentação, pois essas são condições que o trabalho com a arte permite, por serem características intrínsecas a ela própria (LEYTON; ZARDO, 2018).

Ironicamente, também não há consenso de que essa liberdade se dê na maioria dos museus, que também podem servir como instituições que controlam os corpos e buscam disseminar a ordem vigente. Mesmo em museus que têm a missão de colecionar obras de arte, obras essas que costumam colocar em questão funcionamentos e estruturas da ordem social, é possível encontrar contextos carentes de liberdade e experimentação.

\begin{abstract}
Sendo pólos de encontro de muitas pessoas de diversas origens, os museus podem atuar em dois caminhos diferentes: o de contribuir na disseminação de uma lógica vigente e dominante que se queira reproduzir, ou o de trabalhar com o seu público acontecimentos e questões do mundo, libertadas de seu entendimento dominante, permitindo a ressignificação de forma a investigar e criar possibilidades. [...] Enquanto o estudo da história da arte permite ter contato com testemunhos e expressões de diferentes épocas, contribuindo para o desenvolvimento de um olhar sensível e uma reflexão crítica sobre os diversos contextos mundanos passados ou atuais, o exercício de experimentação criativa permite imaginar e instituir possibilidades. (LEYTON, 2017, p. 247)
\end{abstract}

Pelos nossos estudos, debates e reflexões sobre o museu e a escola, sobre arte e educação, chegamos a uma diretriz: de que a existência do museu deve contribuir para que a escola recupere ou mantenha suas características radicais e essenciais: oferecer tempo livre e transformar habilidades em "bens comuns" (...) " $e$, portanto tem o potencial para dar a todos independente de antecedentes, talento natural ou aptidão, o tempo espaço para sair de seu ambiente conhecido, para se superar e renovar (e, portanto, mudar de forma imprevisível) o mundo." (MASSCHELEIN; SIMONS, 2013, Contracapa). Ou seja, a ação educativa em museus deve lutar pela escola em sua

\footnotetext{
${ }^{7}$ Walter Omar Kohan. Notas para uma política do aprender. In: Congresso de Educação Básica - Qualidade na Aprendizagem, Florianópolis: Secretaria de Educação, 2013. Disponível em:

<http://www.pmf.sc.gov.br/arquivos/arquivos/pdf/14_02_2013_16.32.06.c4e8b3dedd1060fab21ed9d35f77adc8.pdf>.
} 
forma: skholé, tempo livre. Essas são características essenciais para promovermos a acessibilidade que mencionamos: a de acessar não só o que já existe, mas o que desejamos que passe a existir. Ou seja, voltando ao argumento de Bavcar, reconhecer como podemos criar situações que não privem a liberdade de quem freqüenta o museu, mas sim promover o exercício experimental de liberdade ${ }^{8}$.

No MAM, uma das ações que faz parte de nosso cotidiano e dessa busca de promover acessibilidade ao que se deseja que exista, é o que chamamos de experiência poética. Mobilizados por uma questão, que pode ser disparada numa visita a uma exposição de um museu, mas pode ser também trazida na sala de aula (seja ministrada na comunidade escolar prisional, ou uma vivência de artes cênicas na universidade, por exemplo), os educandos (visitantes do museu ou alunos) devem partir para o exercício de experimentação criativa, que permite imaginar possibilidades. Para conceituar e compreender o que seriam essas experiências poéticas, partimos de suas etimologias:

\begin{abstract}
A palavra experiência vem do latim experiri, provar (experimentar). O radical é periri, que se encontra também em periculum, perigo. Tanto nas línguas germânicas como nas latinas, a palavra experiência contém inseparavelmente a dimensão de travessia e perigo ${ }^{9}$. O que se inicia numa experiência, não se sabe onde vai chegar. Já a palavra poética, na sua etimologia grega poiesis, significa criação. A raiz poie é a mesma que encontramos no verbo grego poiéo que significa fabricar, compor ou fazer. A experiência poética é uma situação de experimentação por campos em que os resultados não são previsíveis. É a iniciação de um processo em que algo pode ser criado. (LEYTON, 2018, p. 21)
\end{abstract}

Compartilharei aqui alguns aprendizados que vivenciamos no MAM que ilustram onde as experiências poéticas nos levaram:

Com o público surdo aprendemos como o corpo sente e fala. Nosso contato se iniciou no seguinte contexto: visitantes surdos no museu, que não costumavam ter contato com exposições de artes, e nós educadores do MAM, que não conhecíamos a Língua brasileira de sinais, nem as

${ }^{8}$ Esse emblemático conceito formulado pelo crítico de arte Mario Pedrosa, nos anos 60, inspira o título desse artigo. A idéia não foi plenamente explicitada, já que, com o Al-5 e o exílio, Pedrosa teve que se afastar de suas atividades, mas que inspiraria novas gerações no campo das artes, segundo o crítico Lorenzo Mammi, Arte: Ensaios (Cosac Naify, 2015).

9 Jorge Larrosa. Notas sobre a experiência e o saber da experiência. Conferência proferida no I Seminário Internacional de Educação de Campinas, traduzida e publicada, em Leituras SME - Textos-subsídios ao trabalho pedagógico das unidades da Rede Municipal de Educação de Campinas/FUME, 2001. 
culturas surdas. Iniciamos então um curso de formação de educadores surdos, para que eles pudessem receber os outros surdos nas exposições, em sua língua. Descobrimos com essa experiência, além do fato de que estávamos garantindo um direito básico das pessoas surdas, que a fluência na Língua brasileira de sinais era uma competência desses jovens educadores para trabalhar com o público surdo e com ouvintes estudantes de Libras. Percebemos como faltava referências para as crianças surdas, de jovens e adultos surdos atuando em profissões diversas. Passamos a compreender como expressões corporais e faciais traduzem emoções e intensidades. Passamos a conhecer o histórico de opressão a que os surdos foram submetidos, ao não usufruírem de seu direito mais básico, de serem recebidos em sua língua. Atualmente é clara para nós a necessidade de reconhecer e fomentar as capacidades e potencialidades das pessoas surdas, em contraposição aos séculos de opressão e exclusão.

\begin{abstract}
Com o público surdo, aprendemos como o corpo fala. Conhecemos a força de uma língua sem a oralidade. Compreendemos que a ausência da audição gera a criação de comunidades, com língua e cultura próprias, e pudemos nos aproximar delas e desenvolver pesquisas de criações poéticas. Hoje, a Língua Brasileira de Sinais (Libras) integra toda a programação do MAM, em sua potente e expressiva dimensão visual, nos cursos, oficinas, saraus, seminários, flash mobs, filmes, manifestos, narrações de histórias e espetáculos literários e musicais. Essas iniciativas geram a compreensão e a difusão da cultura surda, fortalecem sua identidade e permitem que os surdos desenvolvam ações culturais que conectam sua língua com as linguagens da arte. (LEYTON, 2015, P. 10)
\end{abstract}

Com público cego ou com baixa visão aprendemos a transcender o aspecto visual das coisas. Percebemos que ao descrever uma imagem para uma pessoa que não enxerga, reaprendemos a olhar, nos damos conta dos detalhes que ignoramos por considerarmos óbvios demais, já que estamos vendo. As atividades artísticas em cursos, visitas mediadas e oficinas promovidas para pessoas com deficiência visual junto com o público geral promovem uma significativa sensibilização do olhar. Pessoas cegas e videntes podem compartilhar impressões e percepções de mundo. O público cego também nos mostrou como nós nos atrofiamos de várias maneiras: nosso equilíbrio interno, por depender demasiadamente de pontos de referências visuais, ou a capacidade de se localizar no espaço de acordo com a reverberação do som, por exemplo. 
A presença contínua do público cego ou com baixa visão no MAM, seja como visitantes, como alunos, ou integrando a equipe profissional, nos levou a desenvolver diversos dispositivos e ações: a audiodescrição de imagens, disponibilizada em todas as mostras, busca a equiparação de oportunidades: um chão comum para que os cegos possam partir de um contexto inicial. Os educadores que realizam as mediações das visitas às exposições do museu, além de também realizarem descrições das obras, têm o corpo sensibilizado para compartilhar as impressões e percepções com os visitantes cegos. A permissão para que as obras tridimensionais de cada exposição possam ser tocadas pelos visitantes cegos ou com baixa visão é viabilizada pelo setor do Acervo e pelo setor Educativo, que consultam os responsáveis de cada coleção exposta no museu. E, finalmente, os exercícios de exploração sensorial, as experiências poéticas e os cursos estimulam outras percepções. (...) Os visitantes e alunos do MAM, cegos e que enxergam, estão todos os dias no museu, no poiéin, no fazer, na criação. O convívio com esse público, que gerou a pesquisa e o desenvolvimento de ações que pensam a relação entre o ver e o não ver, nos obrigou a olhar de perto: fomos instigados a tentar enxergar o que transcende o aspecto visual das coisas, e aprendemos sobre as nossas próprias limitações e nosso distanciamento. Essa reflexão sobre distância x proximidade, sobre o ver/espectador $\mathrm{x} o$ estar presente/o que habita o corpo e cria nossa busca por uma permanente construção de um museu de outra percepção. (LEYTON; SANCHES 2018, p. 117)

O público com deficiência intelectual denuncia nossas limitações de compreensão, expressão e de comunicação. Nos faz perceber como uma real escuta permite compartilhar significados entre pessoas que habitam o mundo de maneiras diferentes. Nos torna atento aos nossos preconceitos e nos leva a olhar a maneira que, mesmo sem querer, estamos condicionados a uma determinada forma de agir e se relacionar.

As deficiências intelectuais e as deficiências múltiplas nos evidenciaram como todos atribuem sentidos diferentes a suas experiências e aprendem de formas diversas. Isso significa que, se o educador envolvido não se dispuser realmente a acessar o universo do educando, dificilmente algo ocorrerá. Não é possível ensinar sem aprender, e aprender, nesse sentido, é estar sensível ao que ali está. (LEYTON 2015, p. 11)

O público da saúde mental nos anuncia como nossa sociedade foi configurada pautada pela exclusão do que não é desejado, para a manutenção da ordem vigente. Nos anuncia também que, se conseguirmos suspender nossos estigmas e condicionamentos, podemos abrir um leque de possibilidades de criação imprevisível. Como traz Peter Pál Pelbart (1989) no texto Manicômio mental: a outra face da clausura, esse público traz: "o potencial de desterritorialização: poder secreto e admirável de embaralhar os códigos, subverter as regras do jogo e transpor ou deslocar um limite" 10

\footnotetext{
10 Peter Pál Pelbart. Manicômio mental: a outra face da clausura. Texto apresentado no encontro organizado em São Paulo pelo Plenário de Trabalhadores em Saúde Mental em comemoração ao Dia da Luta Antimanicomial, em 18 de maio de 1989.
} 
E assim seguem nossos aprendizados. Sabemos que alguns deles valem para qualquer pessoa e para qualquer processo educativo, como a sensibilidade necessária ao que ali está na relação entre o educador e o educando. Porém o convívio com a diversidade nos mostra com mais clareza nossas possibilidades e limitações: quais cerceamentos nos são impostos, e quais capacidades acabamos nem explorando, sem sequer nos darmos conta.

\begin{abstract}
Ao presenciar situações como a de um aluno com grave comprometimento motor pintando, desenhando ou esculpindo, ou a de um aluno surdo-cego apreciando uma visita mediada numa exposição de artes visuais, percebemos quão amplas são as possibilidades de se comunicar e aprender. O contato com pessoas com comprometimentos físicos e sensoriais nos leva a olhar para nosso próprio corpo e a ressignificá-lo. Passamos a exercitar sentidos adormecidos e ampliamos nossa percepção. (LEYTON 2015, p. 11)
\end{abstract}

Retornando à questão de Bavcar, na busca de construir um Museu de outra percepção, nos encontramos num exercício constante de perceber nossas potencialidades e nossos aprisionamentos, nossas igualdades e nossas diferenças, nossas escolas e nossos museus. E esses aprendizados que pudemos ter com os diversos públicos são o que nos permitem tomar consciência para ler a realidade tal qual ela se apresenta, e assim podermos pensar, expressa e exercitar como podemos afinal, nela atuar.

\title{
Referências bibliográficas
}

BAVCAR, Evgen. 0 museu de outra percepção. In: LEYTON, Daina. et al. Programa Igual Diferente. São Paulo: Museu de Arte Moderna de São Paulo, 2015.

EIJI, Hugo. Deafhood. In: Cultura surda. Disponível em: <https://culturasurda.net/deafhood>. Acessado em julho de 2018.

FOUCAULT, Michel. Vigiar e punir: nascimento da prisão. Tradução de Lígia M. Ponde Vassalo. Petrópolis: Vozes, 1975.

História da loucura na Idade Clássica. 9. São Paulo: Perspectiva, 1978.

A sociedade punitiva: curso no Collège de France (1972-1973). Trad. Ivone Benedetti. São Paulo: Editora WMF; Martins Fontes, 2015.

KOHAN, Walter Omar e LARROSA, Jorge. Apresentação da coleção. In: LARROSA, Jorge (org.) Elogio da escola. Belo Horizonte: Autêntica, 2017. 
KOHAN, Walter Omar. Notas para uma política do aprender. In: Congresso de Educação Básica Qualidade na Aprendizagem, Florianópolis: Secretaria de Educação, 2013. Disponível em: <http://www.pmf.sc.gov.br/arquivos/arquivos/pdf/14_02_2013_16.32.06.c4e8b3dedd1060fab21 ed9d35f77adc8.pdf>. Acessado em julho de 2018.

LARROSA, Jorge. Notas sobre a experiência e o saber de experiência. In: Revista Brasileira da Educação, no 19, Jan/Fev/Mar/Abr. Rio de Janeiro: ANPED, 2002.

LEYTON, Daina. Programa Igual Diferente. V.1. São Paulo: Museu de Arte Moderna de São Paulo, 2015.

Curar uma exposição sobre a escola: um exercício de pensamento. In: LARROSA, Jorge (org.) Elogio da escola. Belo Horizonte: Autêntica, 2017.

Visitas mediadas + experiências poéticas. In: Educação e acessibilidade: experiências do Museu de Arte Moderna de São Paulo. São Paulo: Museu de Arte Moderna de São Paulo, 2018.

LEYTON, Daina; LUCENA, Cibele e ZATZ, Joana. Aprender para ensinar. In: Programa Igual Diferente. São Paulo: Museu de Arte Moderna de São Paulo, 2015.

LEYTON, Daina; SANCHES, Gregório Ferreira Contreras. Olhar de perto. In: Educação e acessibilidade: experiências do Museu de Arte Moderna de São Paulo. São Paulo: Museu de Arte Moderna de São Paulo, 2018.

LEYTON, Daina; ZARDO, Fernanda Vargas. Educação em deslocamentos. In: Educação e acessibilidade: experiências do Museu de Arte Moderna de São Paulo. São Paulo: Museu de Arte Moderna de São Paulo, 2018.

MASSCHELEIN, Jan e SIMONS, Maarten. Em defesa da escola: uma questão pública. Belo Horizonte: Autêntica, 2013.

PEDROSA, Mário. In: MAMMI, Lorenzo (org.), Arte. Ensaios Críticos - Volume I. São Paulo:

Cosac Naify, 2015.

PELBART, Peter Pál. Manicômio mental: a outra face da clausura. Texto apresentado no encontro organizado pelo Plenário de Trabalhadores em Saúde Mental em comemoração ao Dia da Luta Antimanicomial, São Paulo, 18 de maio de 1989.

Um desejo de asas. In: A nau do tempo-rei: sete ensaios sobre o tempo da loucura. Rio de Janeiro: Imago, 1993. Disponível em:

<http://www.pucsp.br/nucleodesubjetividade/Textos/peter/naudotemporei.pdf>. Acessado em julho de 2018.

RECHIA, Karen Christine; MENDONÇA, Geovana; MENDES, Lunardi e HOEPERS, Ana Maria Preve. Elogio da escola: o desafio de pensar uma forma sem função. In. LARROSA, Jorge (org.) Elogio da escola. Belo Horizonte: Autêntica, 2017. 
| Daina Leyłon

SACKS, Oliver. Vendo vozes: Uma viagem ao mundo dos surdos. São Paulo: Companhia de Letras, 2010.

SANCHES, Gregório Ferreira Contreras. Olhar de perto. In: Educação e acessibilidade: experiências do Museu de Arte Moderna de São Paulo. São Paulo: Museu de Arte Moderna de São Paulo, 2018.

Artigo submetido em 01/07/2019, e aceito em 13/08/2019. 